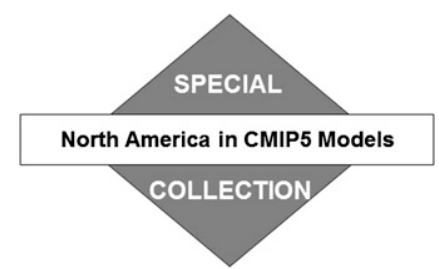

\title{
Multidecadal Climate Variability and the "Warming Hole" in North America: Results from CMIP5 Twentieth- and Twenty-First-Century Climate Simulations*
}

\author{
SANJIV KUMAR \\ Center for Ocean-Land-Atmosphere Studies, Calverton, Maryland \\ JAMES KinTER III AND PAUl A. DiRMEYER \\ George Mason University, Fairfax, Virginia, and Center for Ocean-Land-Atmosphere Studies, \\ Calverton, Maryland \\ ZAITAO PAN \\ Saint Louis University, St. Louis, Missouri \\ JENNIFER ADAMS \\ Center for Ocean-Land-Atmosphere Studies, Calverton, Maryland
}

(Manuscript received 30 July 2012, in final form 28 November 2012)

\begin{abstract}
The ability of phase 5 of the Coupled Model Intercomparison Project (CMIP5) climate models to simulate the twentieth-century "warming hole" over North America is explored, along with the warming hole's relationship with natural climate variability. Twenty-first-century warming hole projections are also examined for two future emission scenarios, the 8.5 and $4.5 \mathrm{~W} \mathrm{~m}^{-2}$ representative concentration pathways (RCP8.5 and RCP4.5). Simulations from 22 CMIP5 climate models were analyzed, including all their ensemble members, for a total of 192 climate realizations. A nonparametric trend detection method was employed, and an alternative perspective emphasizing trend variability. Observations show multidecadal variability in the sign and magnitude of the trend, where the twentieth-century temperature trend over the eastern United States appears to be associated with low-frequency (multidecadal) variability in the North Atlantic temperatures. Most CMIP5 climate models simulate significantly lower "relative power" in the North Atlantic multidecadal oscillations than observed. Models that have relatively higher skill in simulating the North Atlantic multidecadal oscillation also are more likely to reproduce the warming hole. It was also found that the trend variability envelope simulated by multiple CMIP5 climate models brackets the observed warming hole. Based on the multimodel analysis, it is found that in the twenty-first-century climate simulations the presence or absence of the warming hole depends on future emission scenarios; the RCP8.5 scenario indicates a disappearance of the warming hole, whereas the RCP4.5 scenario shows some chance $(10 \%-20 \%)$ of the warming hole's reappearance in the latter half of the twenty-first century, consistent with $\mathrm{CO}_{2}$ stabilization.
\end{abstract}

\footnotetext{
* Supplemental information related to this paper is available at the Journals Online web site: http://dx.doi.org/10.1175/JCLI-D12-00535.s1.
}

Corresponding author address: Sanjiv Kumar, Center for OceanLand-Atmosphere Studies, 4041 Powder Mill Road, Suite 302, Calverton, MD 20705-3106.

E-mail: sanjiv@cola.iges.org

\section{Introduction}

As the earth warms, regional differences in warming rates can help us better understand the mechanisms of the warming. For example, we expect continents to warm faster than oceans based on thermodynamic arguments, and the polar latitudes to warm faster than the tropics or midlatitudes because of snow-surface albedo feedback. Departures from these expectations, such as 


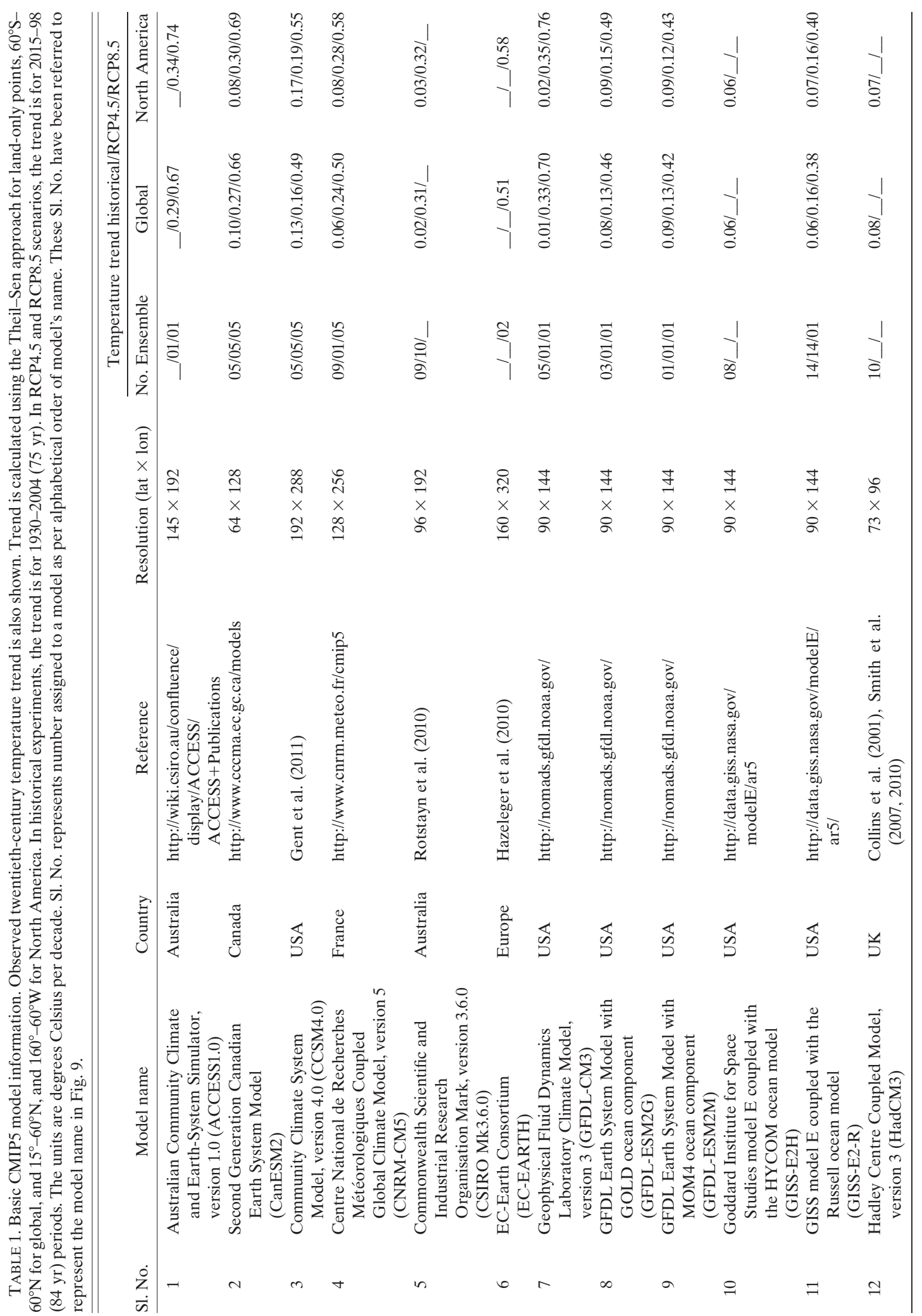




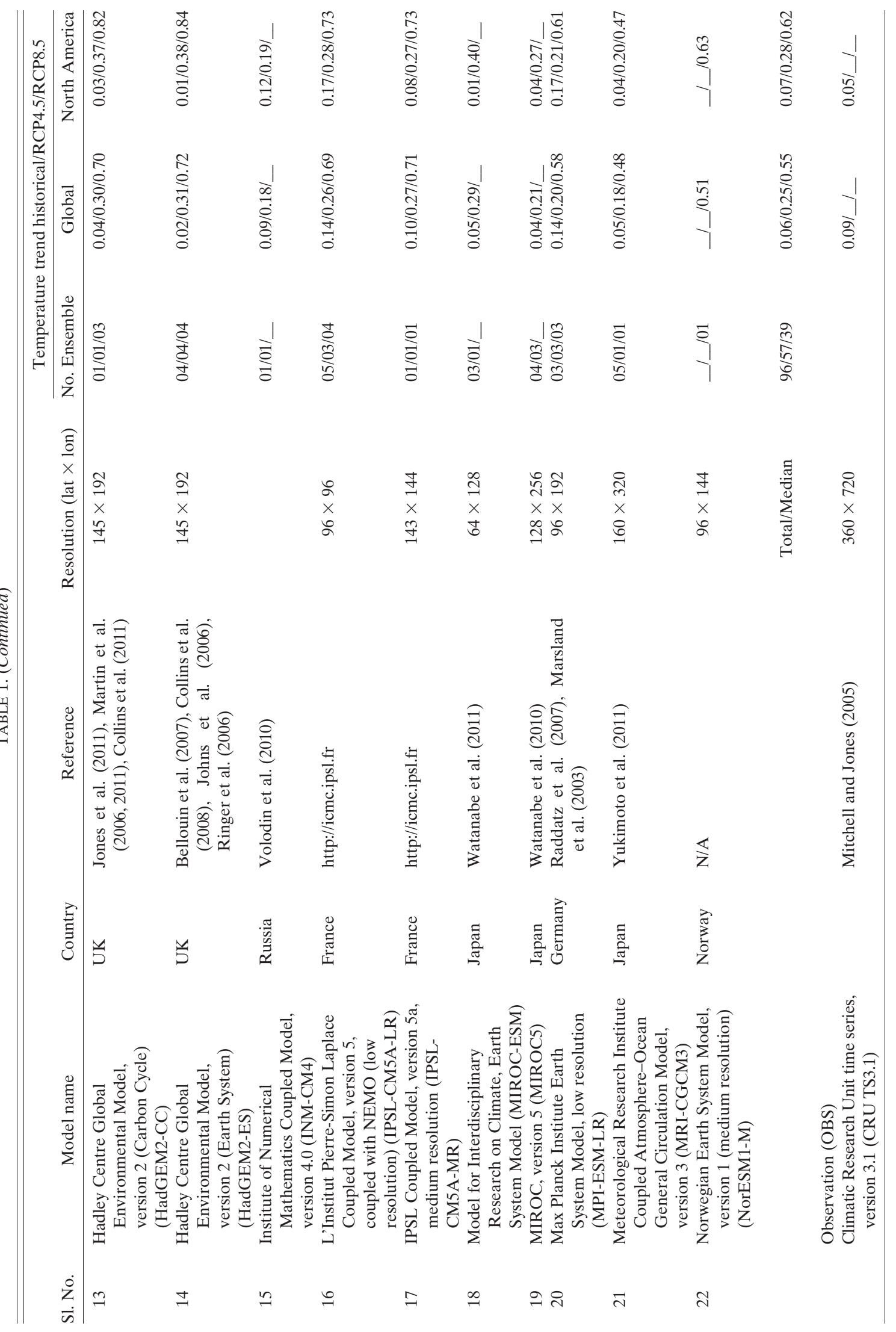


[a] Annual Temperature Trend, 1930-2004
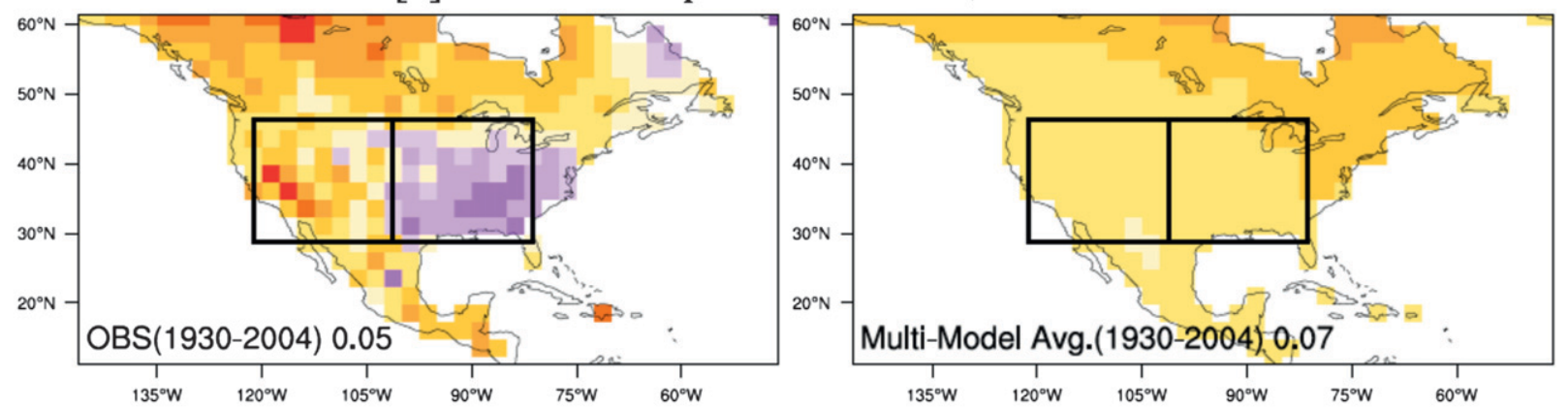

[b] Summer (JJA) Temperature Trend, 1930-2004
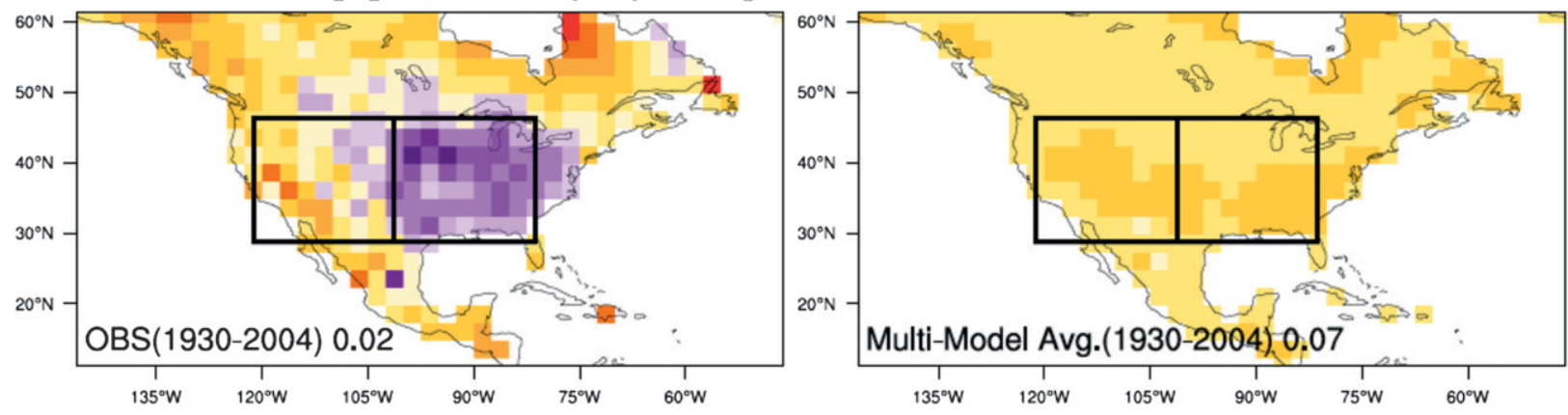

[c] Winter (DJF) Temperature Trend, 1930-2004

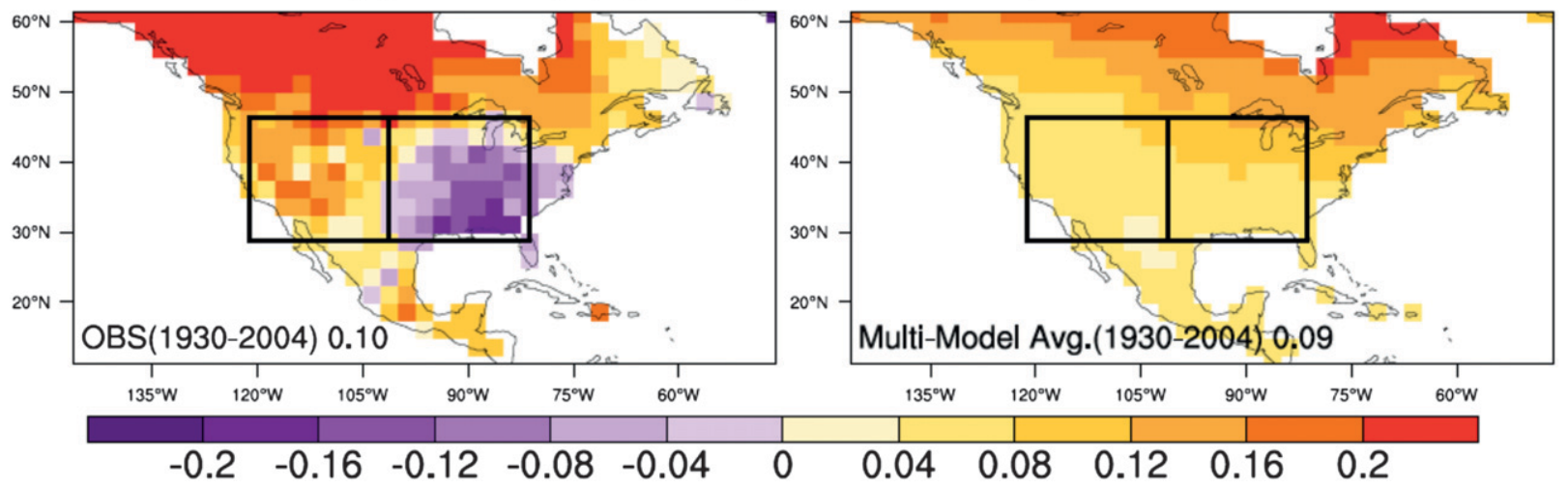

FIG. 1. Warming hole (left) observations and (right) CMIP5 twentieth-century climate simulations for (a) the annual temperature trend, (b) the summer (June-August; JJA) temperature trend, and (c) the winter (December-February; DJF) temperature trend, in degrees Celsius per decade for 1930-2004. The number in each panel represents the North American land-only temperature trend and the spatial average for the entire region shown in the figure. The two boxes represent the eastern and the western United States' regions referred to in subsequent figures.

the so-called "warming hole" in the eastern United States (Pan et al. 2004), can provide clues to the nature of the warming and its relationship with natural climate variability. The models in phase 3 of the Coupled Model Intercomparison Project (CMIP3) were challenged in simulating this warming hole (Kunkel et al. 2006).

Attempts to understand the mechanism that produces the warming hole have led to several investigations in recent years (e.g., Meehl et al. 2012a; Misra et al. 2012; Weaver 2013). While some studies have attributed the warming hole to large-scale decadal oscillations such as the interdecadal Pacific oscillation (IPO), the Pacific decadal oscillation (PDO), and the Atlantic multidecadal oscillation (AMO; Robinson et al. 2002; Kunkel et al. 2006; Wang et al. 2009; Meehl et al. 2012a; Weaver 2013), other studies have highlighted the role of regional-scale hydrologic processes and land-atmosphere interaction (e.g., Pan et al. 2004; Liang et al. 2006; Misra et al. 2012). The most common feature of these studies is investigating the temperature trends for a fixed time window, 
1911-1940
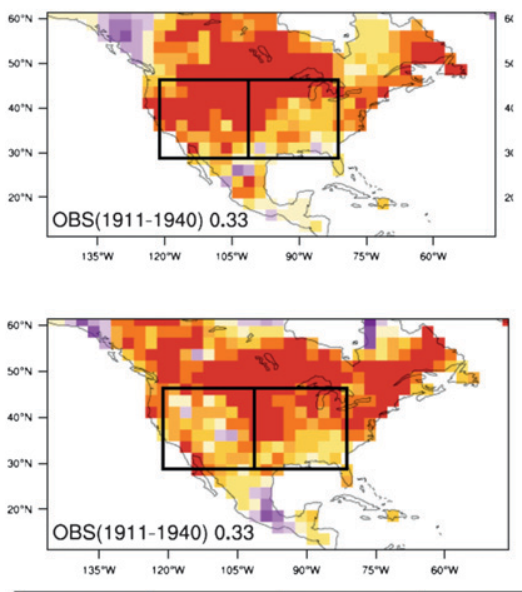

1941-1970

Summer (JJA) Temperature Trend

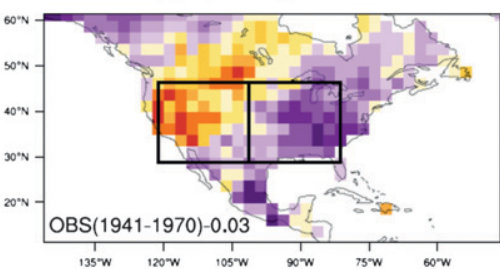

Winter (DJF) Temperature Trend

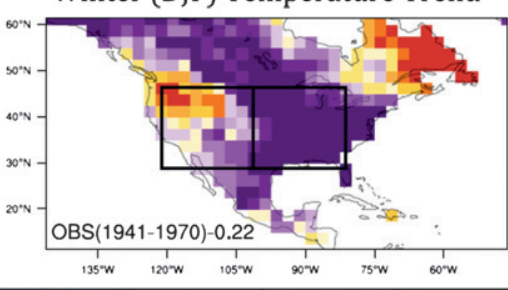

1971-2004
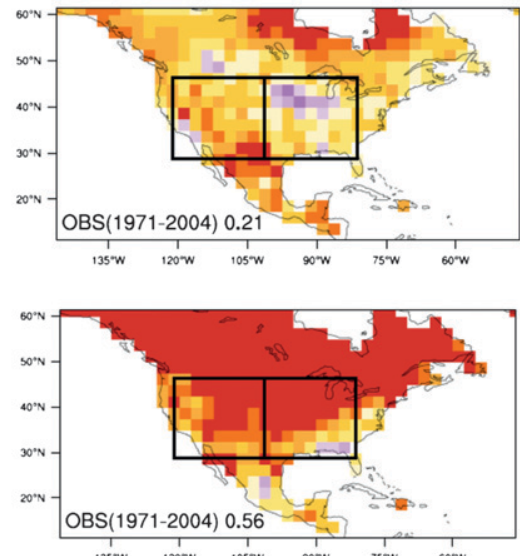

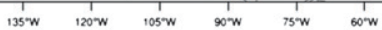

\section{$\begin{array}{lllllllllll}-0.4 & -0.32 & -0.24 & -0.16 & -0.08 & 0 & 0.08 & 0.16 & 0.24 & 0.32 & 0.4\end{array}$}

FIG. 2. Multidecadal spatial and temporal variability in observed "warming hole." (top) Summer and (bottom) winter temperature trends for three nonoverlapping 30-yr periods in the twentieth century are shown: (left) 1911-40, (middle) 1941-70, and (right) 1971-2004, in degrees Celsius per decade. The number in each panel represents the North American land-only temperature trend in the corresponding period and the spatial average for the entire region shown in the figure.

particularly for the second half of the twentieth century. Given the fact that the calculation of trends is strongly influenced by the selected time window (as we will show), and that internally generated climate variability may play an important role in the observed warming hole (Meehl et al. 2012a), further investigation is required. Also, new methodologies are needed to assess climate models' skill in simulating the warming hole, because internally generated decadal climate variability rarely synchronizes in time among different climate simulations or between models and observations.

To address these concerns, we apply a nonparametric trend detection method and an alternative perspective emphasizing trend variability to explore the phase 5 of CMIP (CMIP5) climate models' skill in simulating the twentieth-century warming holes, and their relationship with natural climate variability. We call "trend variability" an alternative perspective because typically trends have been analyzed as monotonically increasing or decreasing features. Modeling studies related to the warming hole are constrained by a given model's parameterizations (e.g., Meehl et al. 2012a). Here, we have adopted a multimodel analysis approach, analyzing a large number of available CMIP5 climate simulations. We have shown results from individual models and their ensemble members in a supplemental section (available online at http://dx.doi.org/10.1175/ JCLI-D-12-00535.s1).

We have also examined twenty-first century warming hole projection results for two future scenarios: 1) the high emission scenario from the $8.5 \mathrm{~W} \mathrm{~m}^{-2}$ representative concentration pathway (RCP8.5) and 2) the relatively low emission scenario of the $4.5 \mathrm{~W} \mathrm{~m}^{-2}$ representative concentration pathway ( $\mathrm{RCP} 4.5)$. We examined the twenty-first-century climate projection results within the context of observed uncertainty determined from the twentieth-century climate simulations from CMIP5. The three main objectives of this study are 1) to evaluate the CMIP5 climate models' skill in simulating the observed twentiethcentury warming hole in North America, 2) to determine the relationship between observed temperature variability and natural multidecadal climate variability, and 3) to assess the twenty-first century warming hole projections in view of the twentieth-century warming hole's simulation uncertainty. Section 2 describes CMIP5 data used and the methods applied. Results are given in section 3 , and section 4 presents a summary discussion and conclusions.

\section{Data and methodology}

We have analyzed 22 CMIP5 climate models listed in Table 1 (note that expansions of all model names are given therein.) We have given preference to a large sample size in different experiments instead of a common set of models/ensembles across all experiments. Thus, we have analyzed 19 CMIP5 climate models (comprising a total of 96 ensemble members) for historical (twentieth century) experiments, 18 CMIP5 climate 


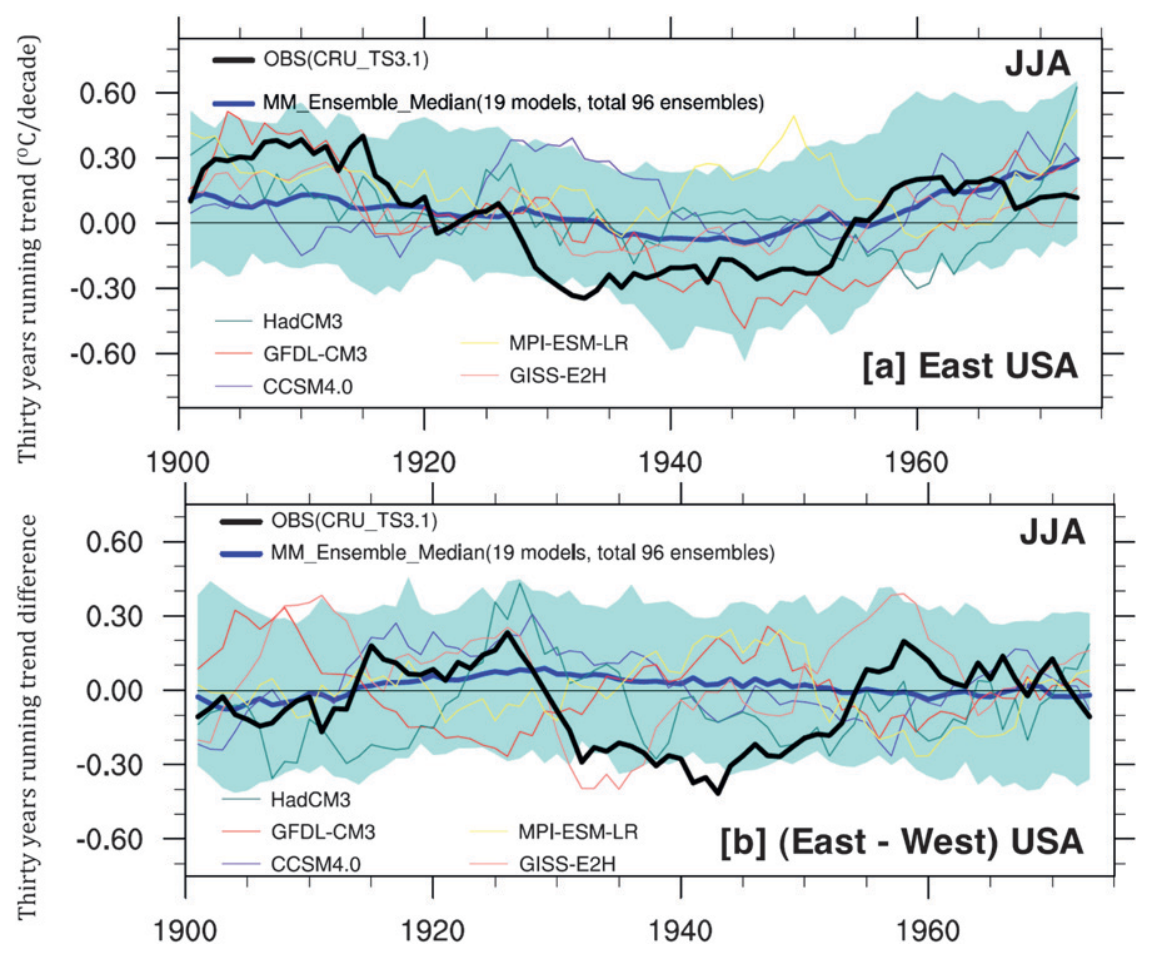

FIG. 3. Temporal variability (multidecadal) in summer temperature trends in (a) the eastern United States and (b) its comparison with the western U.S. summer temperature trend, in degrees Celsius per decade. Eastern and western U.S. region boxes are shown in Figs. 1 and 2. The shaded region shows the $95 \%$ uncertainty range calculated from a total of 96 ensemble members from 19 CMIP5 models. Five sample models (only the first ensemble member from each model) are also shown for comparison.

models (with a total of 57 ensemble members) for the RCP4.5 experiments, and 16 CMIP5 climate models (39 ensemble members) for the RCP8.5 experiments. Model selection for each experiment was primarily driven by the data availability at the time this study was conducted. The historical experiments are standard allforcings climate simulations including anthropogenic greenhouse gas concentrations/emissions, volcanic aerosols, and land use changes for the period 1850-2005 (Taylor et al. 2012). In 2100, $\mathrm{CO}_{2}$-equivalent concentrations are greater than $1370 \mathrm{ppm}$ in the RCP8.5 experiments, and approximately $650 \mathrm{ppm}$ in the RCP4.5 experiments (Moss et al. 2010). For more details on the CMIP5 experiments, please see Taylor et al. (2012).

The Climatic Research Unit time series, version 3.1 (CRU TS3.1), data for temperature are used as observations (Mitchell and Jones 2005). CRU TS3.1 data are available over land points at $0.5^{\circ} \times 0.5^{\circ}$ resolution for 1901-2009. Two climate indices, the AMO and the PDO, are obtained from the National Oceanic and Atmospheric Administration (NOAA) Earth System Research Laboratory (http://www.esrl.noaa.gov/psd/data/ climateindices/list/). The AMO is an index of North
Atlantic Ocean sea surface temperature (SST) anomalies calculated from monthly SST data (Kaplan et al. 1998; Enfield et al. 2001). The PDO is the leading principal component of monthly SST anomalies in the North Pacific Ocean poleward of $20^{\circ} \mathrm{N}$ (Mantua et al. 1997).

All climate models and the CRU TS3.1 data are regridded to a common resolution of $2.5^{\circ} \times 2.5^{\circ}(144 \times 72$ global grid) using an area-average preserving method, and monthly outputs are aggregated to produce mean annual/seasonal time series for temperature.

We have employed a nonparametric trend detection technique. The magnitude of trends is determined by using the Theil-Sen approach (TSA; Sen 1968; Theil 1950). If $x_{1}, x_{2}, \ldots, x_{n}$ is a time series $X_{t}$ of length $n$, then the TSA slope is given by Eq. (1):

$$
\beta=\operatorname{median}\left(\frac{x_{j}-x_{i}}{j-i}\right) \quad \text { for all } i<j
$$

The trend's statistical significance can be determined using different versions of the Mann-Kendall test (see 


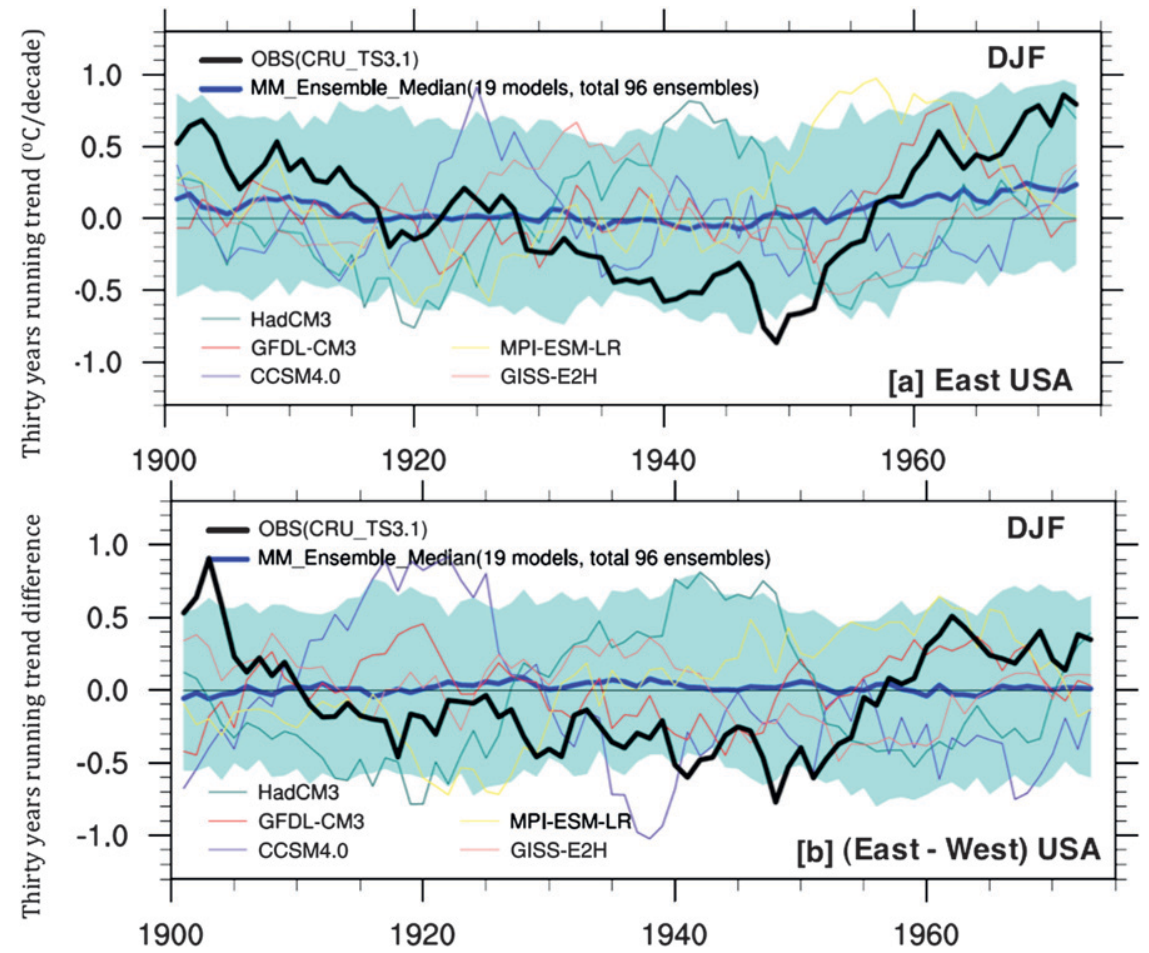

FIG. 4. As in Fig. 3, but for winter.

Kumar et al. 2009 for details). Since the main purpose of this study is to understand the mechanism of the warming hole (a negative temperature trend), the statistical significance test is not employed in this study. The statistical significance of the temperature trend in CMIP5 twentieth-century climate simulations is presented elsewhere (Kumar et al. 2013).

The 30-yr running trend is calculated starting in 1901 (constrained by observation availability) in the twentieth century, and in 2006 in the twenty-first century. A 30 -yr period is selected as the running window length to represent the multidecadal climate variability in North America. It is demonstrated later that the 30 -yr period is an appropriate choice for the window length, and this length does not bias the results.

We have employed the frequency domain analysis to study multidecadal climate variability in the North Atlantic. We performed a fast Fourier transform (FFT; Bloomfield 1976) on detrended anomaly time series of the North Atlantic temperature $\left(Y_{t}=y_{1}, y_{2}, \ldots, y_{n}\right)$. Let us say Eq. (2) represents $y_{t}$ in the frequency domain:

$y_{t}=\sum_{j=1}^{(n-1) / 2}\left[a_{j} \cos \left(\frac{2 \pi t j}{n}\right)+b_{j} \sin \left(\frac{2 \pi t j}{n}\right)\right]$ for $n=$ odd

and

$$
\begin{aligned}
y_{t}= & \sum_{j=1}^{(n / 2)-1}\left[a_{j} \cos \left(\frac{2 \pi t j}{n}\right)+b_{j} \sin \left(\frac{2 \pi t j}{n}\right)\right] \\
& +a_{n / 2} \cos \left(\frac{2 \pi t}{2}\right) \text { for } n=\text { even }
\end{aligned}
$$

where the Fourier series coefficients $a_{j}$ and $b_{j}$ were determined through FFT. The harmonic $j$ represents number of full wave cycles in the entire analysis period ( $n$ years). The $j$ th harmonic's frequency $w_{j}$, amplitude $A_{j}$, and power $p_{j}$ are given below:

$$
\begin{aligned}
& w_{j}=\frac{j}{n}, \\
& A_{j}=\sqrt{a_{j}^{2}+b_{j}^{2}}, \text { and } \\
& p_{j}=\frac{a_{j}^{2}+b_{j}^{2}}{2} .
\end{aligned}
$$

We tested the signal power in the $k$ th Fourier harmonic relative to residual harmonics using Hartley's test (Thibos 2003). The null hypothesis for Hartley's test is that the signal power in the $k$ th harmonic is zero. To reject the null hypothesis Hartley's test statistics $H>F_{2,2 R}$, where $H$ is given in Eq. (6), $F_{2,2 R}$ is Fisher's $F$ 
[a] Annual Temperature Trend, 1930-2004

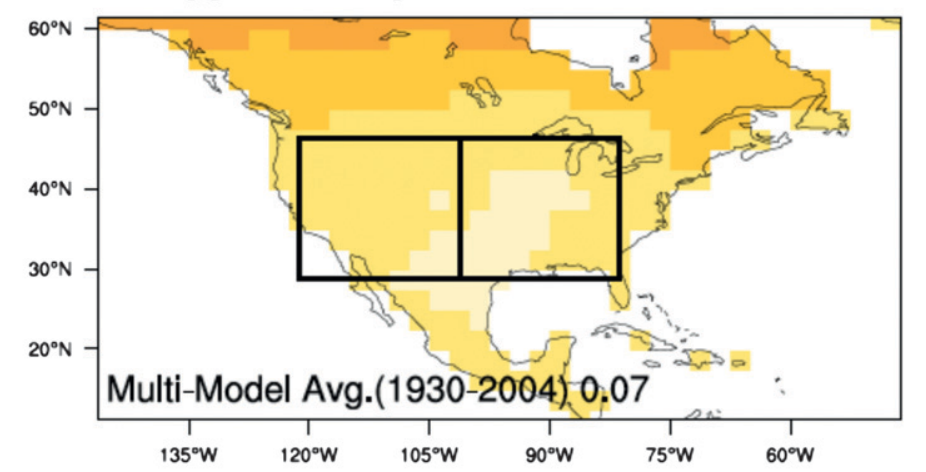

[b] Summer (JJA) Temperature Trend, 1930-2004

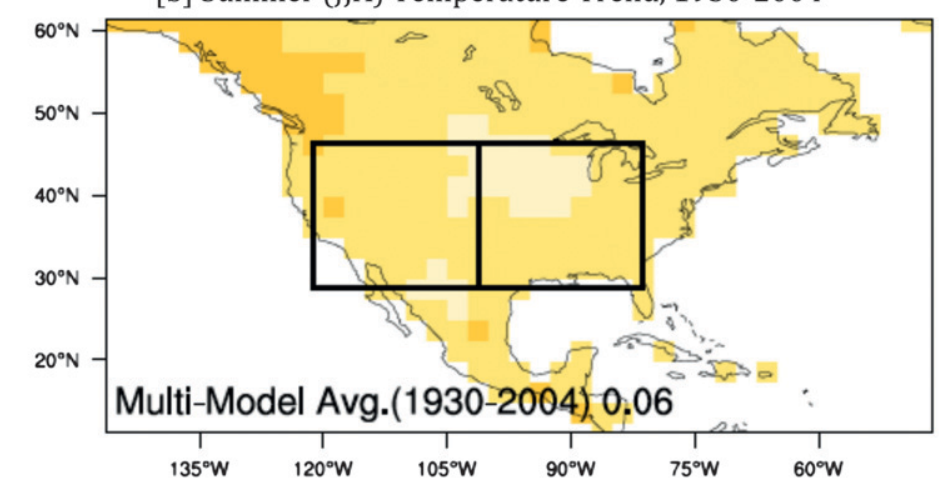

[c] Winter (DJF) Temperature Trend, 1930-2004

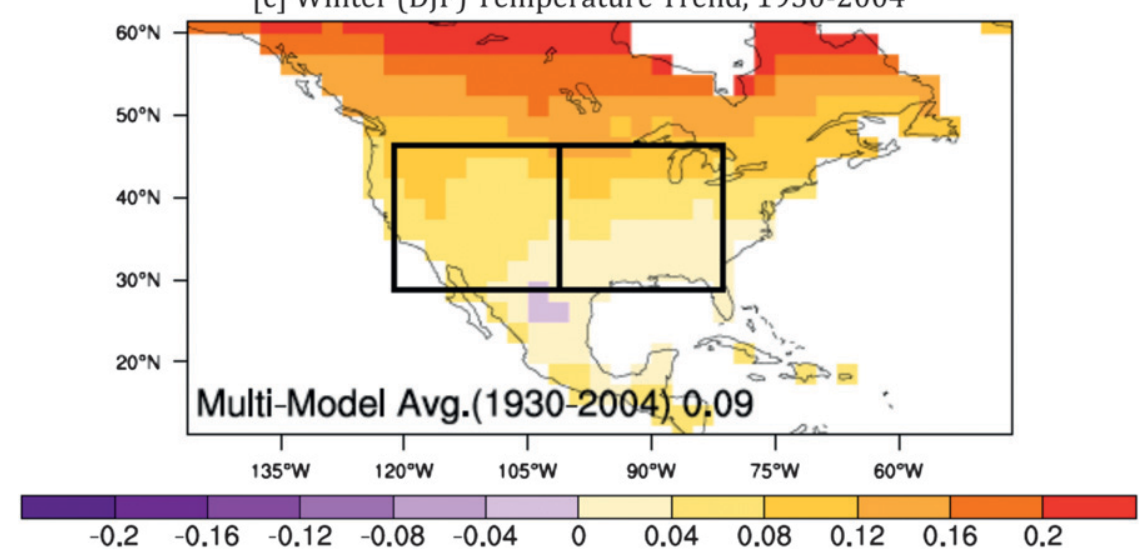

FIG. 5. As in Fig. 1 (right), but for one selected ensemble member from each model, showing the highest spatial correlation for North America land annual temperature trend (1930-2004). Units are degrees Celsius per decade.

distribution with 2 and $2 R$ degrees of freedom, and $2 R=$ $(n-3)$. The derivation for Hartley's test can be found in Thibos (2003, chapter 9):

$$
H=\frac{p_{k}}{\frac{1}{R} \sum_{j \neq k} p_{j}} \sim F_{2,2 R} .
$$

Finally, we have explored the relationship between models' skill in simulating the warming hole and that in simulating low-frequency variability in the North Atlantic.

\section{Results \\ a. Twentieth-century temperature trend}

Figure 1 shows the long-term (1930-2004) temperature trend over North America. In observations, most of the eastern United States shows a negative temperature 


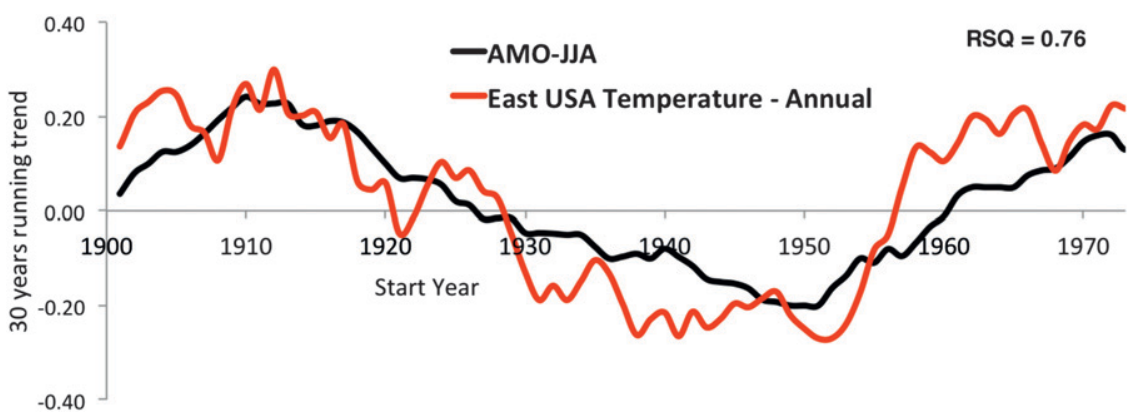

FIG. 6. Multidecadal variability in AMO and eastern United States' temperature trend. Also see Table 2 for more details. Units are degrees Celsius per decade.

trend, which changes in extent between summer and winter. During summer a stronger negative temperature trend is present in the northern central United States, while during winter a stronger negative trend is present over the southeastern United States. The multimodel average temperature trends in CMIP5 twentieth-century climate simulations are shown in the right panels of Fig. 1. The multimodel average results do not show either a negative temperature trend or an east-west gradient in temperature trends as found in the observations. These results suggest that CMIP5 models may have limited skill in simulating aspects of the warming hole in North America (see supplemental Figs. S1-S3 for individual model results). Alternatively, it could be that the warming hole is not a robust response of anthropogenic forcing in CMIP5 twentieth-century climate simulations. We next investigate the natural climate variability aspect.

Figure 2 shows the observed temperature trend during three nonoverlapping climatological periods ( $\geq 30 \mathrm{yr}$ ) in the twentieth century: 1911-40, 1941-70, and 1971-2004. The observed temperature trends show considerable variability in both space and time. For example, the period 1911-40 does not show a negative temperature trend, but the period 1941-70 shows a strong negative temperature trend over the eastern United States, as well as many other parts of North America, including central and western Canada during winter. The period 1971-2004 demonstrates the fastest warming among three climatological periods shown in Fig. 2. The warming trend in the period 1971-2004 may be a combination of anthropogenically forced global warming and natural variability. During 1971-2004, a weak negative temperature trend is observed in the northern central United States in summer, and the negative temperature trend almost disappears in winter. These results warrant a closer look into trend variability.

Figures 3 and 4 show the 30-yr running temperature trends (starting in 1901) in the eastern United States during summer and winter, respectively. In these figures, the trends are referred to by their starting year (e.g., the trend plotted at 1901 represents the trend over the 190130 period). A comparison of the eastern United States' temperature trend with that in the western United States is also presented in these figures. Box regions in Figs. 1 and 2 show the extent of the eastern and the western United States in this analysis as well as all subsequent analysis (eastern United States: $30^{\circ}-47^{\circ} \mathrm{N}, 80^{\circ}-100^{\circ} \mathrm{W}$; western United States: $\left.30^{\circ}-47^{\circ} \mathrm{N}, 100^{\circ}-120^{\circ} \mathrm{W}\right)$. The observed temperature trend exhibits multidecadal variability. For example, all negative temperature trends are clustered in the 1925-55 decades for both summer and winter. A positive temperature trend is observed in the early part (1901-20) as well as the latter part of the twentieth century (1955 onward) over the eastern United Sates. The east-west pattern in the temperature trend also shows multidecadal variability.

Figures 3 and 4 also display results from CMIP5 twentieth-century climate simulations (see supplemental Figs. S4-S7 for individual model results). All ensemble members of a given model are considered individually in this analysis, as well as in all following analyses. The $95 \%$ model spread range, referred to as the simulated envelope of trend variability, mostly

TABLE 2. Variance explained by the AMO and PDO; 30-yr running trend in eastern United States' annual, winter, and summer temperature trends. The $95 \%$ confidence interval statistical significance of the RSQ (i.e., $r^{2}$ ) is calculated considering seven independent members in the sample, shown in boldface numbers.

\begin{tabular}{clccc}
\hline \hline & & \multicolumn{3}{c}{ Eastern U.S. temperature } \\
\cline { 3 - 5 } RSQ & & Annual & DJF & JJA \\
\hline AMO (1901-2004) & Annual & $\mathbf{0 . 6 0}$ & $\mathbf{0 . 4 8}$ & $\mathbf{0 . 5 0}$ \\
& DJF & $\mathbf{0 . 4 9}$ & 0.40 & 0.37 \\
& JJA & $\mathbf{0 . 7 6}$ & $\mathbf{0 . 6 2}$ & $\mathbf{0 . 7 0}$ \\
PDO (1901-2004) & Annual & 0.17 & 0.15 & 0.29 \\
& DJF & 0.16 & 0.12 & 0.30 \\
& JJA & 0.22 & 0.19 & 0.31 \\
\hline
\end{tabular}




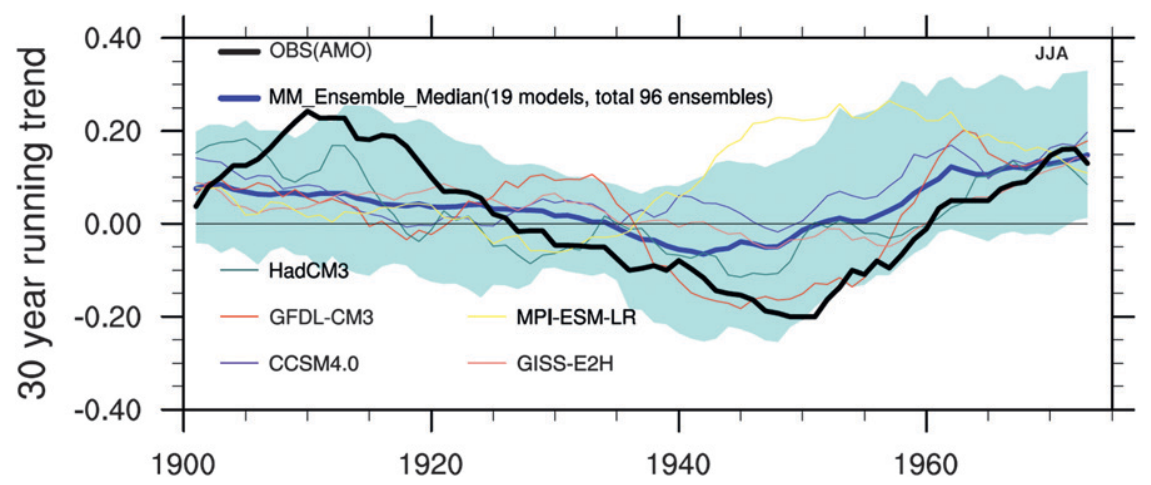

FIG. 7. Twentieth-century summer AMO signal (30-yr running trend) in CMIP5 climate simulations. Shaded region shows $95 \%$ uncertainty range calculated from a total of 96 ensemble members from 19 CMIP5 models. Units are degrees Celsius per decade. Five sample models (only the first ensemble member from each model) are also shown for comparison.

brackets the observed multidecadal variability in temperature trend. The multimodel ensemble median captures the observed trend's sign (positive or negative), but it poorly represents the observed trend's magnitude. In most cases, except for summers in 1960-74, the multimodel ensemble median provides a very conservative trend estimate. For example, from the 1960s onward, the observations show a $0.5^{\circ} \mathrm{C}$ decade $^{-1}$ or greater winter warming in the eastern United States, whereas the multimodel ensemble median only shows a $0.2^{\circ} \mathrm{C}$ decade ${ }^{-1}$ warming. The multimodel median east-west trend difference is mostly zero, which is not the case in the observations.

These results suggest that the multimodel ensemble average may not be the best tool to investigate a regionally confined feature like the warming hole. These results also suggest that some internally generated "natural" climate variability contributes to the warming hole signal in the region. These internally generated signals do not synchronize well across different climate simulations, resulting in a muted signal in the multimodel ensemble average/median. Figure 5 shows the multimodel mean temperature trend from only one selected ensemble member from each model, showing the highest spatial correlation with observations in the North America region $\left(15^{\circ}-60^{\circ} \mathrm{N}, 160^{\circ}-60^{\circ} \mathrm{W}\right.$, land only) for the 1930-2004 annual temperature trend. Although such subjective selection did not result in a negative temperature trend, it did show a region with a reduced warming trend relative to the surrounding regions over the northern central United States during summer, and over the southeastern United States during winter. This suggests that selected CMIP5 twentieth-century climate simulations may have some skill in simulating aspects of the warming hole in North America (see supplemental Figs. S8-S10 for individual model results). We also believe that a similar result can be obtained from selected unforced/preindustrial climate simulations, which again emphasizes the role of natural climate variability in the warming hole.

The multidecadal variability is generally associated with a low-frequency variability of the oceans because of their large reservoir capacity. Figure 6 and Table 2 show the association of the eastern United States' 30-yr running temperature trends with the observed AMO and PDO during the twentieth century. The observed temperature trend is strongly correlated (statistically significant) with the AMO, whereas no statistically significant correlation is found with the PDO. Previous studies (e.g., Wang et al. 2009; Weaver 2013) have

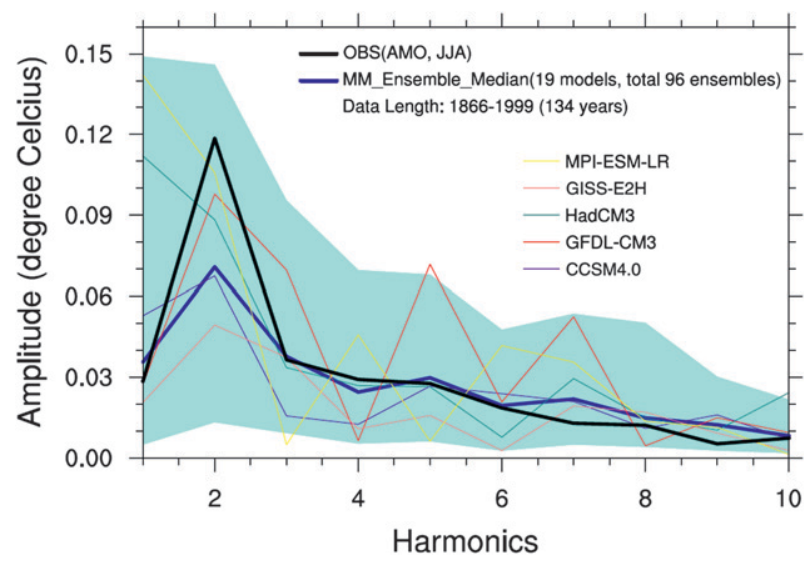

FIG. 8. Frequency analysis for observed and simulated JJA AMO. Harmonics represent the number of cycles per 134 years (full data length). Shaded region shows $95 \%$ uncertainty range calculated from a total 96 ensemble members from 19 CMIP5 models. Peak amplitude for the second harmonic represents 67 years of the AMO cycle. Five sample models (only the first ensemble member from each model) are also shown for comparison. 
found that the PDO influenced summer temperature variations in the central United States/Great Plains region in the latter half of the twentieth century. It is likely that a different study area (the eastern United States) and the extended analysis period (1901-2004) are contributing to the different results between previous studies and this one. The summer AMO [JuneAugust (JJA)] explains $76 \%$ of the variance in the annual temperature trend, $70 \%$ of the variance in the summer temperature trend, and $62 \%$ of the variance in the winter temperature trend (all statistically significant). The winter AMO [December-February (DJF)] does not show statistically significant correlations for the most part. Hence it is not discussed further. Note that the AMO curve is smoother than the time series of the observed eastern United States' temperature trend in Fig. 6. This could be because of a number of reasons, including 1) higher variability in the land observations relative to the ocean and/or 2) the AMO time series is a reanalysis product compared with real observations over the land.

We have further explored the CMIP5 models' skill in simulating the JJA AMO. Figure 7 shows the $30-y r$ running temperature trend in the North Atlantic $\left(0^{\circ}-\right.$ $60^{\circ} \mathrm{N}, 5^{\circ}-75^{\circ} \mathrm{W}$, ocean only) from CMIP5 twentiethcentury climate simulations and observations. The $95 \%$ model spread range generally brackets the observations. However, the observations pass through the edges of the simulated envelope at their peaks (e.g., 1910 and 1950s). This result indicates that CMIP5 models may have a smaller amplitude relative to the observed for AMO variability, as shown in the multimodel median time series as well as some individual models in Fig. 7 (see supplemental Fig. S11 for all individual model results).

Figure 8 shows the JJA AMO variability in a frequency domain using a Fourier transform method (see supplemental Fig. S12 for individual model results). In this analysis, a longer time series 1862-2004 is considered; a 10-yr moving average is applied to the AMO anomaly time series after removing the linear trend from the data to be consistent with Enfield et al. (2001), resulting in the 1866-1999 (134 yr) time series. The peak amplitude appears in the second harmonic, corresponding to a 67-yr cycle, in the observations as well as the multimodel ensemble median. The second harmonic's power is significantly greater (28 times) than the average power of other frequencies in the observations (Fig. 9). Hence, we argue that the 65- to 70-yr cycle shown in Figs. 6 and 7 in particular, and Figs. 3 and 4 (top panels only) in general, is not a by-product of the 30-yr moving trend; rather, it can be associated with lowfrequency variability in the North Atlantic. Although

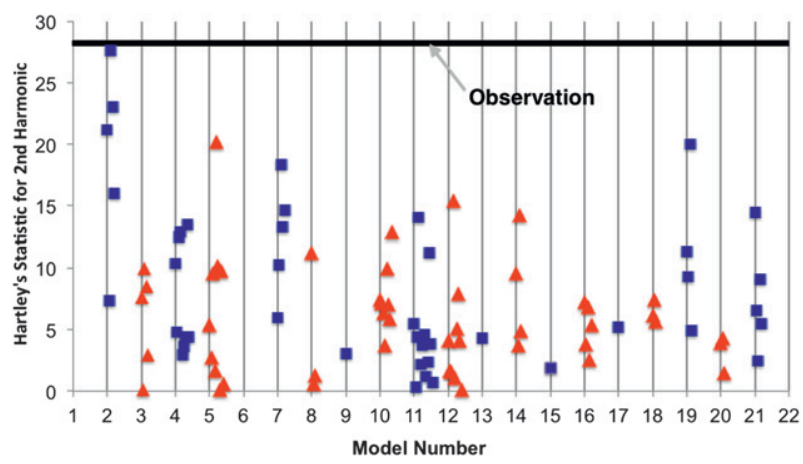

FIG. 9. Power of the second harmonic relative to average power of residual harmonics ( 1 and 3-10, shown in Fig. 7) represented as a ratio of the two quantities called Hartley's statistics. Hartley's statistics values greater than 6 are statistically significant at the $99 \%$ confidence interval. For model number, please refer to Table 1. All ensemble members of the given model are shown individually.

many of CMIP5 climate simulations show statistically significant power in the second harmonic $(H>6)$, the relative power of the second harmonic remains significantly lower than in the observations except for model 2 (Fig. 9). There is a large spread among models in the relative power of their second harmonics (Table 3 ); its effect on the warming hole simulations is investigated next.

We have summarized individual model results for the warming hole simulation skill in Table 3. For models having more than one ensemble member, we calculated model results for each individual ensemble member and then averaged across different ensemble members in the given model. The relative power in the second harmonic ranges from 1.9 (INMCM4) to 19.0 (CanESM2). Several models (e.g., CanESM2, CNRM-CM5, GFDL-CM3, GFDL-ESM2G, HadGEM2-CC, HadGEM2-ES, IPSLCM5A-LR, MRI-CGCM3, MIROC5, and MIROC-ESM) show higher power in the second harmonics relative to other harmonics (see supplemental Fig. S12), which results in higher second harmonic power in the multimodel ensemble median result (Fig. 8). However, several models also have higher power relative to observations in other harmonics (e.g., harmonics 5 and 7 in the GFDL-CM3 model; Fig. 8), resulting in lower relative power of the second harmonic in model simulations relative to observations (Fig. 9). Since higher power in harmonics other than the second harmonic is not common across different models, the multimodel ensemble median result is similar to observations for other harmonics (Fig. 8).

The relative power in the second harmonics is positively correlated with the warming hole-related model performance across 19 CMIP5 models, and is statistically significant for JJA AMO simulations (Table 3). 
TABLE 3. Individual model performances in capturing features related to the warming hole. The numbers in boldface indicate statistically significant correlation results at a 95\% confidence interval. Six models show an overall positive NSE*; these are shown in boldface letters. Column 3 indicates Hartley's statistics for the second harmonic shown in Fig. 9. For models having more than one ensemble member, we calculated results for each individual ensemble member and then averaged across all ensemble members in the given model. The quantitative measures NSE (Nash and Sutcliff 1970) and RSQ (i.e., $r^{2}$ ) evaluate models' performances relative to the observations (see related figures in the supplemental material). Sl. No. is as given in Table 1.

\begin{tabular}{|c|c|c|c|c|c|c|c|c|c|c|c|c|}
\hline \multirow[b]{2}{*}{ Sl. No. } & \multirow[b]{2}{*}{ Model name } & \multirow[b]{2}{*}{ H. stat. for 2 nd har. } & \multicolumn{2}{|c|}{$\begin{array}{c}\text { JJA AMO } \\
\text { 30-yr run } \\
\text { trend } \\
\end{array}$} & \multicolumn{2}{|c|}{$\begin{array}{l}\text { JJA eastern } \\
\text { U.S. } 30-y r \\
\text { run trend } \\
\end{array}$} & \multicolumn{2}{|c|}{$\begin{array}{l}\text { DJF eastern } \\
\text { U.S. 30-yr } \\
\text { run trend }\end{array}$} & \multicolumn{2}{|c|}{$\begin{array}{l}\text { Annual east- } \\
\text { ern U.S. } 30- \\
\text { yr run trend } \\
\end{array}$} & \multicolumn{2}{|c|}{$\begin{array}{c}\text { Average } \\
\text { values }\end{array}$} \\
\hline & & & NSE & RSQ & NSE & RSQ & NSE & RSQ & NSE & RSQ & NSE & RSQ \\
\hline 2 & CanESM2 & 19.0 & 0.32 & 0.45 & 0.04 & 0.33 & -0.05 & 0.17 & 0.12 & 0.36 & 0.11 & 0.33 \\
\hline 3 & CCSM4.0 & 5.8 & -0.24 & 0.11 & -0.54 & 0.20 & -0.67 & 0.09 & -0.40 & 0.13 & -0.46 & 0.13 \\
\hline 4 & CNRM-CM5 & 7.7 & 0.11 & 0.23 & -0.56 & 0.20 & -0.17 & 0.25 & -0.12 & 0.26 & -0.19 & 0.23 \\
\hline 5 & CSIRO Mk3.6.0 & 6.7 & 0.19 & 0.36 & -0.33 & 0.37 & 0.00 & 0.15 & 0.07 & 0.44 & -0.02 & 0.33 \\
\hline 7 & GFDL-CM3 & 12.5 & 0.48 & 0.56 & 0.02 & 0.39 & -0.03 & 0.12 & 0.35 & 0.51 & 0.21 & 0.40 \\
\hline 8 & GFDL-ESM2G & 4.4 & -0.39 & 0.18 & -0.05 & 0.20 & -0.80 & 0.16 & -0.52 & 0.04 & -0.44 & 0.14 \\
\hline 9 & GFDL-ESM2M & 3.1 & 0.12 & 0.16 & 0.37 & 0.37 & 0.28 & 0.40 & 0.46 & 0.49 & 0.30 & 0.36 \\
\hline 10 & GISS-E2H & 7.5 & 0.32 & 0.46 & -0.19 & 0.15 & -0.40 & 0.11 & -0.39 & 0.08 & -0.16 & 0.20 \\
\hline 11 & GISS-E2-R & 4.1 & -0.10 & 0.20 & 0.12 & 0.21 & -0.25 & 0.16 & -0.01 & 0.26 & -0.06 & 0.21 \\
\hline 12 & HadCM3 & 4.4 & 0.03 & 0.25 & -0.39 & 0.12 & -0.70 & 0.06 & -1.06 & 0.05 & -0.53 & 0.12 \\
\hline 13 & HadGEM2-CC & 4.3 & 0.44 & 0.68 & 0.07 & 0.42 & 0.29 & 0.39 & 0.47 & 0.58 & 0.32 & 0.52 \\
\hline 14 & HadGEM2-ES & 8.1 & 0.50 & 0.59 & -0.92 & 0.24 & -0.59 & 0.10 & -0.17 & 0.33 & -0.30 & 0.32 \\
\hline 15 & INMCM4 & 1.9 & 0.01 & 0.09 & -0.97 & 0.15 & -0.47 & 0.12 & -0.90 & 0.18 & -0.58 & 0.14 \\
\hline 16 & IPSL-CM5A-LR & 5.2 & -0.86 & 0.25 & -0.50 & 0.12 & -0.44 & 0.08 & -0.80 & 0.16 & -0.65 & 0.15 \\
\hline 17 & IPSL-CM5A-MR & 5.2 & -0.28 & 0.05 & -0.24 & 0.06 & 0.03 & 0.13 & 0.45 & 0.52 & -0.01 & 0.19 \\
\hline 18 & MIROC-ESM & 6.4 & 0.44 & 0.48 & -0.03 & 0.27 & 0.27 & 0.35 & 0.26 & 0.54 & 0.24 & 0.41 \\
\hline 19 & MIROC5 & 11.4 & 0.43 & 0.46 & 0.11 & 0.21 & 0.36 & 0.40 & 0.33 & 0.59 & 0.31 & 0.42 \\
\hline 20 & MPI-ESM-LR & 3.2 & -0.81 & 0.06 & -0.55 & 0.04 & -0.61 & 0.02 & -0.94 & 0.15 & -0.73 & 0.07 \\
\hline \multirow[t]{3}{*}{21} & MRI-CGCM3 & 7.6 & 0.13 & 0.18 & -0.02 & 0.20 & -0.23 & 0.14 & -0.17 & 0.22 & -0.07 & 0.19 \\
\hline & $\begin{array}{l}\text { Correl. with H. Sat. } \\
\text { for second harmonic }\end{array}$ & & 0.48 & 0.51 & 0.26 & 0.36 & 0.28 & 0.07 & 0.38 & 0.29 & 0.42 & 0.40 \\
\hline & Observation & 28.2 & & & & & & & & & & \\
\hline \multirow[t]{5}{*}{ Model spread } & Maximum & 19.0 & 0.50 & 0.68 & 0.37 & 0.42 & 0.36 & 0.40 & 0.47 & 0.59 & 0.32 & 0.52 \\
\hline & Minimum & 1.9 & -0.86 & 0.05 & -0.97 & 0.04 & -0.80 & 0.02 & -1.06 & 0.04 & -0.73 & 0.07 \\
\hline & Mean & 6.8 & 0.04 & 0.31 & -0.24 & 0.22 & -0.22 & 0.18 & -0.16 & 0.31 & -0.14 & 0.25 \\
\hline & Standard dev. & 4.0 & 0.41 & 0.19 & 0.36 & 0.11 & 0.37 & 0.12 & 0.51 & 0.19 & 0.35 & 0.13 \\
\hline & Standard error & 0.9 & 0.09 & 0.04 & 0.08 & 0.03 & 0.09 & 0.03 & 0.12 & 0.04 & 0.08 & 0.03 \\
\hline
\end{tabular}

* Here NSE $=1-\sum_{i=1}^{n}\left(\mathrm{Sm}_{i}-\mathrm{Ob}_{i}\right)^{2} / \sum_{i=1}^{n}\left(\mathrm{Ob}_{i}-\overline{\mathrm{Ob}}\right)^{2}$ where $i=1,2, \ldots, 73$ corresponding to $1901,1902, \ldots, 1973 ; \mathrm{Sm}_{i}$ and $\mathrm{Ob}_{i}: \mathrm{model}$ simulation and observation corresponding to time index $i$; $\overline{\mathrm{Ob}}$ : observation mean (1901-73). NSE values range from $-\infty$ to 1 , NSE $=1$ indicates a perfect model; NSE $>0$ indicates model simulation is skillful relative to observation mean (a positive skill); and NSE < 0 indicates observation mean is better than model simulations.

Only three models (CanESM2, GFDL-CM3, and MIROC5) show relative power in the second harmonic greater than 10; all three models also show overall positive skill [average Nash-Sutcliffe efficiency coefficient $(\mathrm{NSE})>0$ ] in simulating the warming hole-related features (Table 3). Out of the remaining 16 models, GFDL-ESM2M, HadGEM2-CC, and MIROC-ESM also show an overall positive skill in simulating the warming hole-related features (Table 3). Hence, we argue that the relative power in the second harmonic is a good indicator of model skill in simulating the warming hole. We also recognize that in some model simulations factors other than the AMO (which we have not investigated in this study) can result in warming hole features (e.g., the GFDL ESM2M model). The converse is also true; for example, the model with the highest power in the second harmonic (CanESM2) does not show the best performance for the warming hole simulations (Table 3).

Results from the twentieth-century CMIP5 climate simulations presented in this section suggest that a minor fraction of CMIP5 climate models (6 out of 19 models) have a positive skill in simulating the observed warming hole. The $95 \%$ spread range among models bracket the observed variability in regional temperature trends, which suggests that the multimodel ensemble reproduces the observed variance in temperature trend even if each model has limited skill, individually. This 


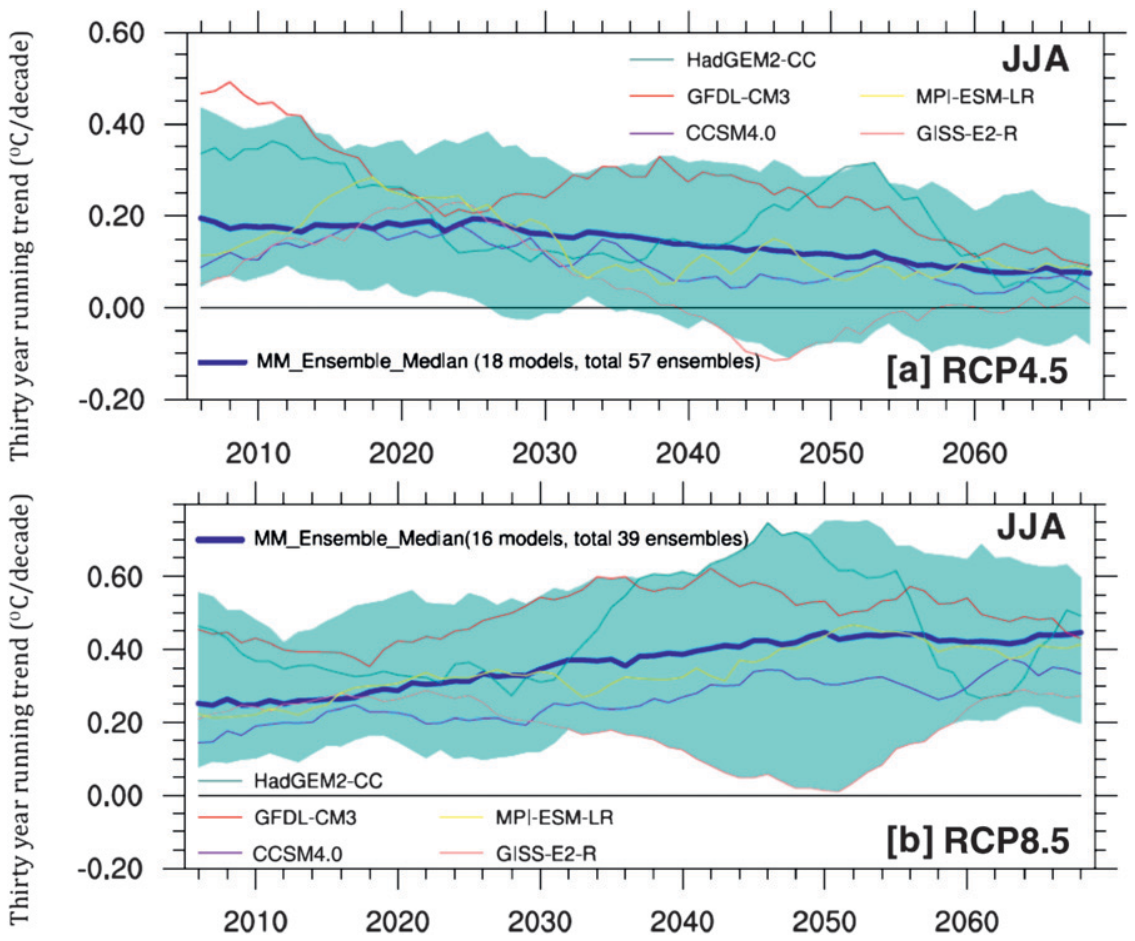

FIG. 10. Twenty-first century summer AMO projection from CMIP5 climate simulations. The shaded region shows $95 \%$ uncertainty range calculated from a total of 57 ensemble members from 18 CMIP5 models in the (a) RCP4.5 scenario and from a total of 39 ensemble members from 16 CMIP5 models in the (b) RCP8.5 scenario. Five sample models (only the first ensemble member from each model) are also shown for comparison.

result also indicates that there is some fidelity in the model simulations. Within this context of known uncertainty in CMIP5 twentieth-century climate simulations, the twenty-first-century climate projections for the warming hole are presented in the next section.

\section{b. Twenty-first century temperature trend}

The North American warming rate (temperature trend) in the twenty-first century is 4 times higher in the $\mathrm{RCP} 4.5$ scenario $\left(0.28^{\circ} \mathrm{C}\right.$ decade $\left.^{-1}\right)$ and 9 times higher in the RCP8.5 scenario $\left(0.62^{\circ} \mathrm{C}\right.$ decade $\left.^{-1}\right)$ than the twentieth-century warming rate $\left(0.07^{\circ} \mathrm{C}\right.$ decade $\left.^{-1}\right)$ in CMIP5 climate simulations (Table 1 ). The higher rate of the twenty-first-century warming in North America is consistent with a similar higher warming rate at global scales (Table 1).

Figures 10a and 10b show 30-yr running JJA temperature trends in the North Atlantic from CMIP5 twenty-first century climate projections in the RCP4.5 and RCP8.5 scenarios, respectively (see supplemental Figs. S13 and S14 for individual model results). The median rate of North Atlantic warming continuously increases in the RCP8.5 scenario, whereas the North Atlantic warming rate decreases in the RCP4.5 scenario, particularly in the latter half of the twenty-first century, consistent with the $\mathrm{CO}_{2}$ emissions' stabilization in the RCP4.5 scenario (Moss et al. 2010; Meehl et al. 2012b). The $95 \%$ spread range among models does not contain a negative temperature trend for the RCP8.5 scenario (Fig. 10b), but there are some negative temperature trends in the latter half of twenty-first century in the RCP4.5 scenario ( $10 \%$ of the shaded region is below the zero line, all in the latter half of the twenty-first century in Fig. 10a).

Figures 11 and 12 show the twenty-first century 30-yr running temperature trends in the eastern United States in the RCP4.5 and RCP8.5 scenarios, respectively (see supplemental Figs. S15-S18 for individual model results). Similar to the North Atlantic warming rate, the temperature trend in the eastern United States declines in the RCP4.5 scenario and increases in the RCP8.5 scenario, particularly in summer. In the last two decades of the twenty-first century, the winter temperature trend in the RCP8.5 scenario has either stabilized or slightly declined for some unknown reason (Fig. 12b). In summer, the $95 \%$ spread range among models does not contain a negative temperature trend in the RCP8.5 scenario (Fig. 12a), and the $95 \%$ spread range among 


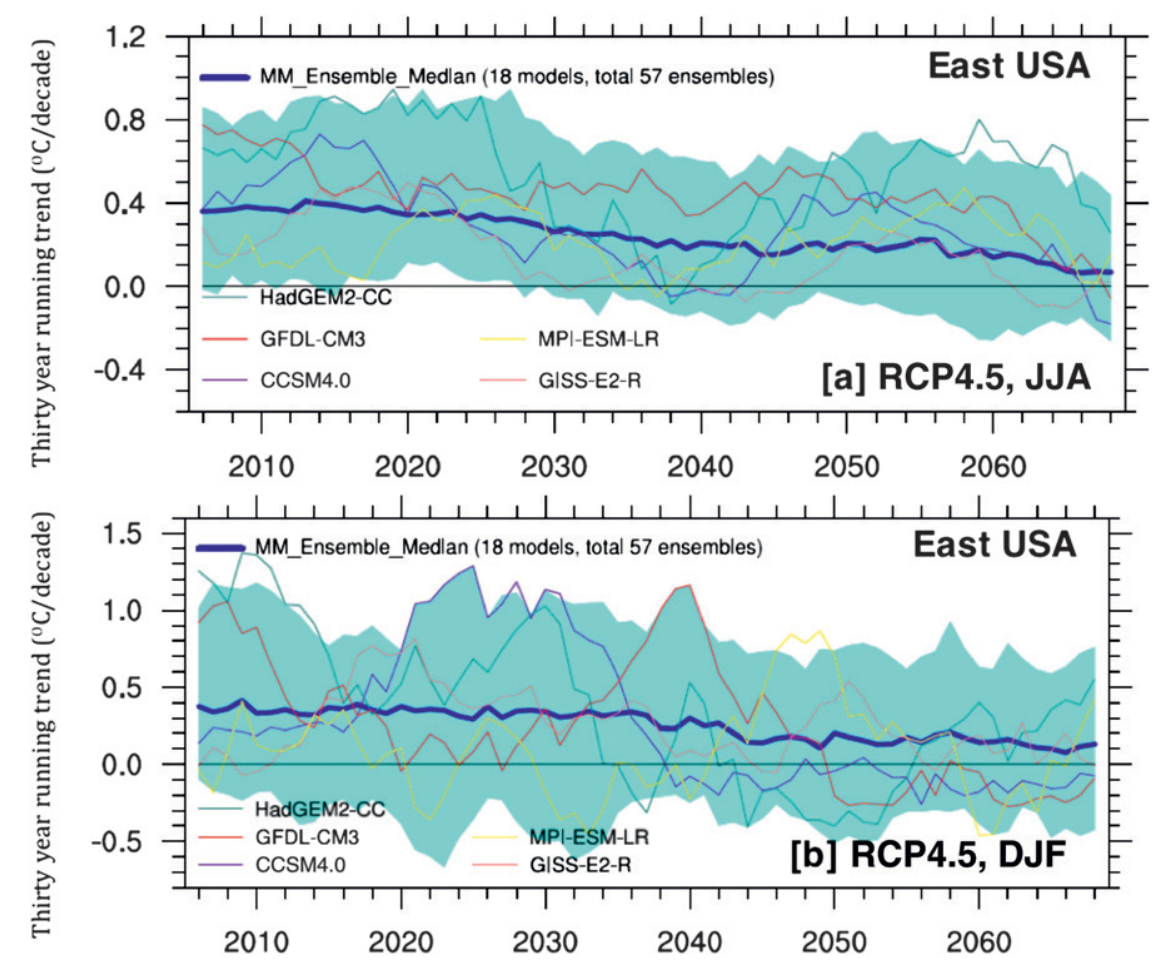

FIG. 11. As in Fig. 10a, but for twenty-first-century eastern U.S. temperature trend projections during (a) JJA and (b) DJF.

models does contain negative temperature trends in some ensemble members during the latter half of the twenty-first century in the RCP4.5 scenario (Fig. 11a; $10 \%$ of the shaded region is below the zero line). In winter, there are some negative temperature trends throughout the twenty-first century in the RCP4.5 scenario simulations (Fig. 11b; 30\% of the shaded region is below the zero line), and only few negative temperature trends, particularly in the first half of twenty-first century in the RCP8.5 scenario (Fig. 12b; 11\% of the shaded region is below the zero line).

The twenty-first-century simulations results from the six models that showed a positive skill in the twentiethcentury warming hole simulations (CanESM2, GFDLCM3, GFDL-ESM2M, HadGEM2-CC, MIROC5, and MIROC-ESM) are generally consistent with the multimodel ensemble results presented in the last two paragraphs. For example, these six models show a declining JJA North Atlantic warming trend in the RCP4.5 scenario and an increasing JJA North Atlantic warming trend in the RCP8.5 scenario, although some of these simulations have a prominent multidecadal variability signal (e.g., the HadGEM2-CC twenty-first-century simulation; see supplemental Figs. S13 and S14; note that for RCP8.5 scenario only four of these six models were available). Similarly, all twenty-first-century climate simulations by CanESM2, GFDL-CM3, GFDL-ESM2M, and HadGEM2-CC show a nonnegative JJA warming trend in the eastern United States throughout the twentyfirst century (see supplemental Fig. S17). The trend variability envelope for the east-west temperature trend difference in the twenty-first century is similar to the twentieth-century results (see supplemental Figs. S19-S21).

\section{Discussion and conclusions}

Using an alternative perspective emphasizing trend variability, we have shown that temperature trends, often associated with global warming, are not monotonic features, at least at regional scales. Observations show multidecadal variability in the sign and magnitude of trends. The twentieth-century temperature trend in the eastern United States appears to be associated with lowfrequency (multidecadal) variability in the North Atlantic temperature observations. The greenhouse gas emission-based global warming affects the regional temperature trend by changing/shifting the trend variability envelope. For example, $40 \%$ of the trend variability envelope is negative in the twentieth-century eastern United States' temperature trend simulations (i.e., $40 \%$ of the shaded regions in Figs. $3 \mathrm{a}$ and $4 \mathrm{a}$ are 


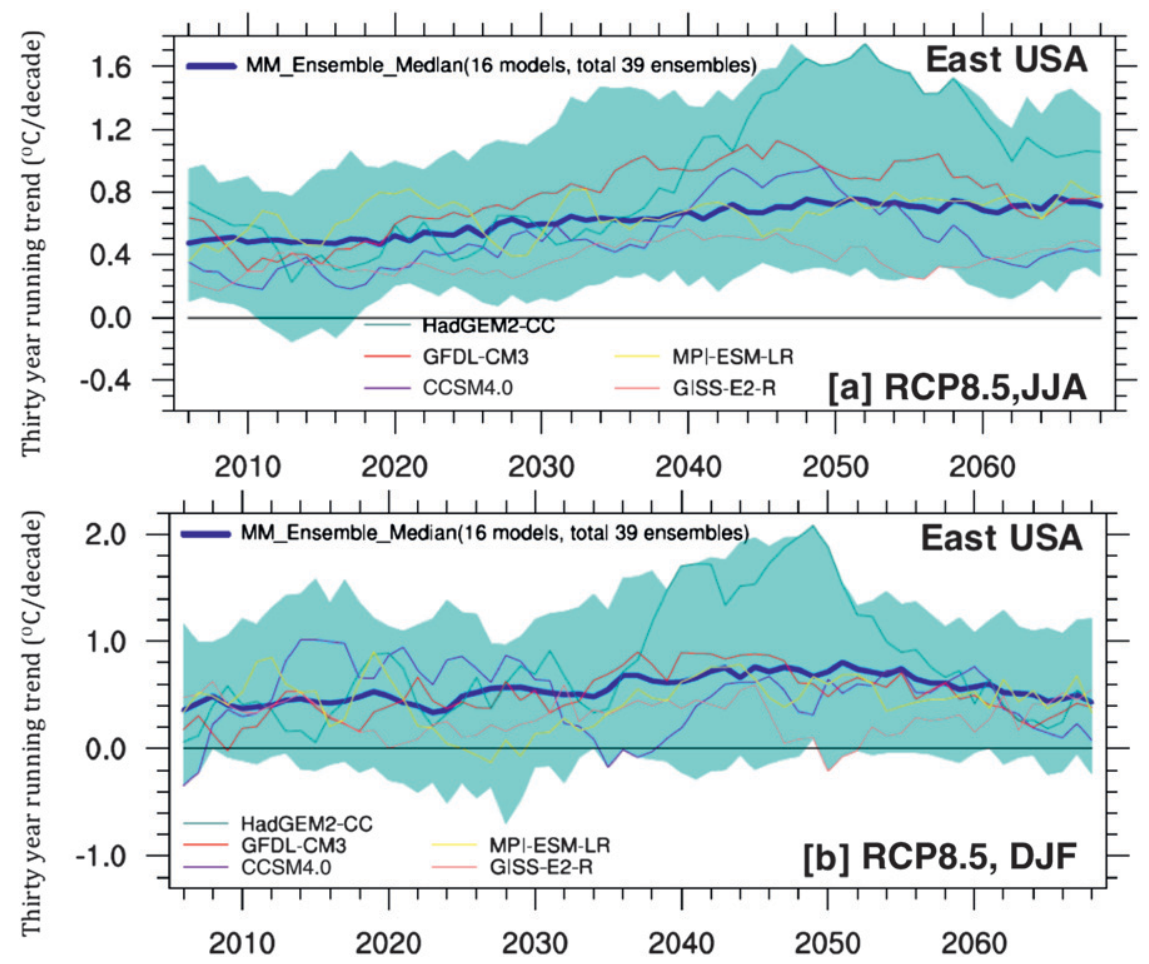

FIG. 12. As in Fig. 10b, but for twenty-first-century eastern U.S. temperature trend projections during (a) JJA and (b) DJF.

below the zero line). However, none of the climate simulations shows negative summer temperature trends in the RCP8.5 scenario, and only $10 \%$ of all climate simulations show negative summer temperature trends in the latter half of the twenty-first century in the RCP4.5 scenario, associated with $\mathrm{CO}_{2}$ stabilization. Similar results are also observed for the North Atlantic temperature trends.

The trend variability envelope simulated by multiple CMIP5 climate models (19 models, with a total of 96 ensemble members) brackets the observed warming hole. Pan et al. (2013) found the nine simulations (out of 100 ) reproduced the temporal variation of warming hole temperature very well. Hence, we argue that although individual models (also see Meehl et al. 2012b) as well as the multimodel mean/median (this study) may have limited skill in capturing regionally detailed features such as the warming hole, the simulated multimodel trend variability envelope provides a credible variability range for the observations. Since a similar analysis was not conducted with CMIP3 climate model simulations, we cannot conclude that CMIP5 models have significantly improved relative to CMIP3 models with respect to their warming hole representations. However, we confirm that, similar to earlier CMIP3 findings (Kunkel et al. 2006), the warming hole is not a robust response to the external climate forcing in CMIP5 models.

Based on a single model simulation, Meehl et al. (2012a) anticipated that the warming hole would disappear in the twenty-first century with the ongoing greater warming in the western United States relative to the eastern United States. Based on multiple CMIP5 climate models simulations and two emission scenarios, we find that the variability range of the model-simulated east-west temperature trend difference does not change from the twentieth century to the twenty-first century, and the multimodel median east-west temperature trend difference remains near zero in both the twentieth- and twenty-first-century climate simulations. Hence, we suggest that east-west temperature trend difference may not be a robust metric to study the warming hole in model simulations.

Model simulations show that the absence or presence of the warming hole in the twenty-first century would depend upon the emission pathway. Model consensus suggests that if we stabilize $\mathrm{CO}_{2}$ emissions, then there are some chances $(10 \%-20 \%)$ that the warming hole may reappear in the second half of the twenty-first century (RCP4.5). However, if we follow the highest emission pathway (RCP8.5), the warming hole would disappear in the twenty-first century. Many theories 
for the warming hole have been proposed, including internally generated climate variability, multidecadal climate variability, land-atmosphere interactions, regionalscale hydrologic processes, and aerosol effects (Robinson et al. 2002; Pan et al. 2004; Liang et al. 2006; Wang et al. 2009; Leibensperger et al. 2012; Meehl et al. 2012a; Weaver 2013). Hence, we can expect a warming hole to appear in climate simulations for a number of different reasons. Using a longer time series, we have shown that the observed warming hole is closely associated with the multidecadal oscillation in the North Atlantic (65- to 70 -yr cycle). Most CMIP5 climate models simulate significantly lower "relative power" in the North Atlantic multidecadal oscillations than observed. We also found that models that have relatively higher skills in simulating the North Atlantic multidecadal oscillations also have higher chances ( 3 out of 3 ) of a positive skill in the warming hole simulations relative to remaining models (3 out of 16). Investigating what causes multidecadal oscillations in the North Atlantic is beyond the scope of this work. Further research is needed to reconcile different warming hole theories, so that models are right for the right reason.

Acknowledgments. The authors acknowledge the support of NOAA's Climate Program Office Modeling, Analysis, Predictions, and Projections (MAPP) Program as part of the CMIP5 Task Force. This project received support from the following grants: National Science Foundation (NSF) 0947837, NSF 0830068, NOAA NA09OAR4310058, and National Aeronautics and Space Administration (NASA) NNX09AN50G. We acknowledge the World Climate Research Programme's Working Group on Coupled Modelling, which is responsible for CMIP, and we thank the climate modeling groups (listed in Table 1 ) for producing and making available their model output. For CMIP, the U.S. Department of Energy's Program for Climate Model Diagnosis and Intercomparison provides coordinating support and leads development of software infrastructure in partnership with the Global Organization for Earth System Science Portals. We are thankful to three anonymous reviewers for their helpful comments.

\section{REFERENCES}

Bellouin, N., and Coauthors, 2007: Improved representation of aerosols for HadGEM2. Hadley Centre Tech. Note 73, 42 pp. [Available online at http://www.metoffice.gov.uk/media/pdf/ 8/f/HCTN_73.pdf.]

Bloomfield, P., 1976: Fourier Analysis of Time Series: An Introduction. John Wiley and Sons, $258 \mathrm{pp}$.
Collins, M. S., F. B. Tett, and C. Cooper, 2001: The internal climate variability of HadCM3, a version of the Hadley Centre Coupled Model without flux adjustments. Climate Dyn., 17, 61-81.

Collins, W. J., and Coauthors 2008: Evaluation of the HadGEM2 model. Hadley Centre Tech. Note 74, 47 pp. [Available online at http://www.metoffice.gov.uk/media/pdf/8/7/HCTN_74.pdf.]

— , and Coauthors, 2011: Development and evaluation of an Earth-system model-HadGEM2. Geosci. Model Dev. Discuss., 4, 997-1062, doi:10.5194/gmdd-4-997-2011.

Enfield, D. B., A. M. Mestas-Nuñez, and P. J. Trimble, 2001: The Atlantic multidecadal oscillation and its relation to rainfall and river flows in the continental U.S. Geophys. Res. Lett., 28, 2077-2080.

Gent, P. R., and Coauthors, 2011: The Community Climate System Model version 4. J. Climate, 24, 4973-4991, doi:10.1175/ 2011JCLI4083.1.

Hazeleger, W., and Coauthors, 2010: EC-Earth: A seamless Earthsystem prediction approach in action. Bull. Amer. Meteor. Soc., 91, 1357-1363.

Johns, T. C., and Coauthors, 2006: The new Hadley Centre climate model HadGEM1: Evaluation of coupled simulations. J. Climate, 19, 1327-1353.

Jones, C. D., and Coauthors, 2011: The HadGEM2-ES implementation of CMIP5 centennial simulations. Geosci. Model Dev., 4, 543-570, doi:10.5194/gmd-4-543-2011.

Kaplan, A., M. A. Cane, Y. Kushnir, A. C. Clement, M. B. Blumenthal, and B. Rajagopalan, 1998: Analysis of global sea surface temperatures 1856-1991. J. Geophys. Res., 103 (C9), $18567-18589$.

Kumar, S., V. Merwade, J. Kam, and K. Thurner, 2009: Streamflow trends in Indiana: Effects of long term persistence, precipitation and subsurface drains. J. Hydrol., 374, 171-183.

,-- J. Kinter III, and D. Niyogi, 2013: Evaluation of temperature and precipitation trends and long-term persistence in CMIP5 twentieth-century climate simulations. J. Climate, in press.

Kunkel, K. E., X.-Z. Liang, J. Zhu, and Y. Lin, 2006: Can CGCMs simulate the twentieth century "warming hole" in the central United States. J. Climate, 19, 4137-4153.

Leibensperger, E. M., and Coauthors, 2012: Climatic effects of 1950-2050 changes in US anthropogenic aerosols-Part 2: Climate response. Atmos. Chem. Phys., 12, 3349-3362.

Liang, X.-Z., J. Pan, J. Zhu, K. E. Kunkel, J. X. L. Wang, and A. Dai, 2006: Regional climate model downscaling of the U.S. summer climate and future change. J. Geophys. Res., 111, D10108, doi:10.1029/2005JD006685.

Mantua, N. J., S. R. Hare, Y. Zhang, J. M. Wallace, and R. C. Francis, 1997: A Pacific interdecadal climate oscillation with impacts on salmon production. Bull. Amer. Meteor. Soc., 78, 1069-1079.

Marsland, S. J., H. Haak, J. H. Jungclaus, M. Latif, and F. Röske, 2003: The Max-Planck-Institute global ocean/sea ice model with orthogonal curvilinear coordinates. Ocean Modell., 5, 91-127.

Martin, G. M., M. A. Ringer, V. D. Pope, A. Jones, C. Dearden, and T. J. Hinton, 2006: The physical properties of the atmosphere in the new Hadley Centre Global Environmental Model, HadGEM1. Part I: Model description and global climatology. J. Climate, 19, 1274-1301.

_- and Coauthors, 2011: The HadGEM2 family of Met Office Unified Model climate configurations. Geosci. Model Dev., 4, 723-757, doi:10.5194/gmd-4-723-2011.

Meehl, G. A., J. M. Arblaster, and G. Branstator, 2012a: Mechanisms contributing to the warming hole and the consequent 
U.S. east-west differential of heat extremes. J. Climate, $\mathbf{2 5}$ 6394-6408.

_ , and Coauthors, 2012b: Climate system response to external forcings and climate change projections in CCSM4. J. Climate, 25, 3661-3683.

Misra, V., J.-P. Michael, R. Boyles, E. P. Chassignet, M. Griffin, and J. J. O'Brien, 2012: Reconciling the spatial distribution of the surface temperature trends in the southeastern United States. J. Climate, 25, 3610-3618.

Mitchell, T. D., and P. D. Jones, 2005: An improved method of constructing a database of monthly climate observations and associated high-resolution grids. Int. J. Climatol., 25, 693-712, doi:10.1002/joc.1181.

Moss, R. H., and Coauthors, 2010: The next generation of scenarios for climate change research and assessment. Nature, 463, 747 756, doi:10.1038/nature08823.

Nash, J. E., and J. V. Sutcliffe, 1970: River flow forecasting through conceptual models: Part I. A discussion of principles. J. Hydrol., 10, 282-290.

Pan, Z., R. W. Arritt, E. S. Takle, W. J. Gutowski Jr., C. J. Anderson, and M. Segal, 2004: Altered hydrologic feedback in a warming climate introduces a "warming hole." Geophys. Res. Lett., 31, L17109, doi:10.1029/2004GL020528.

_ - X. Liu, S. Kumar, Z. Gao, and J. Kinter, 2013: Inter-model variability and mechanism attribution of central and southeastern U.S. anomalous cooling in the twentieth century as simulated by CMIP5 models. J. Climate, in press.

Raddatz, T. J., and Coauthors, 2007: Will the tropical land biosphere dominate the climate-carbon cycle feedback during the twenty-first century? Climate Dyn., 29, 565-574, doi:10.1007/ s00382-007-0247-8.

Ringer, M. A., and Coauthors, 2006: The physical properties of the atmosphere in the new Hadley Centre Global Environmental Model, HadGEM1. Part II: Aspects of variability and regional climate. J. Climate, 19, 1302-1326.

Robinson, W. A., R. Reudy, and J. E. Hansen, 2002: General circulation model simulations of recent cooling in the eastcentral United States. J. Geophys. Res., 107, 4748, doi:10.1029/ 2001JD001577.

Rotstayn, L., M. Collier, M. Dix, Y. Feng, H. Gordon, S. O'Farrell, I. Smith, and J. Syktus, 2010: Improved simulation of Australian climate and ENSO-related climate variability in a GCM with an interactive aerosol treatment. Int. J. Climatol., 30, 1067-1088, doi:10.1002/joc.1952.

Sen, P. K., 1968: Estimates of the regression coefficients based on Kendall's tau. J. Amer. Stat. Assoc., 63, 1379-1389.

Smith, D. M., S. Cusack, A. W. Colman, C. K. Folland, G. R. Harris, and J. M. Murphy, 2007: Improved surface temperature prediction for the coming decade from a global climate model. Science, 317, 796-799.

— , R. Eade, N. J. Dunstone, D. Fereday, J. M. Murphy, H. Pohlman, and A. A. Scaife, 2010: Skilful multi-year predictions of Atlantic hurricane frequency. Nat. Geosci., 3, 846849, doi:10.1038/ngeo1004.

Taylor, K. E., R. J. Stouffer, and G. A. Meehl, 2012: An overview of CMIP5 and the experiment design. Bull. Amer. Meteor. Soc., 93, 485-498.

Theil, H., 1950: A rank-invariant method of linear and polynomial analysis, Part 3. Ned. Akad. Wet. Proc., 53, 13971412.

Thibos, L. N., 2003: Fourier Analysis for Beginners. Indiana University. [Available online at http://research.opt.indiana.edu/ library/fourierbook/title.html.]

Volodin, E. M., N. A. Dianskii, and A. V. Gusev, 2010: Climate model INMCM4.0. Izv. Atmos. Oceanic Phys., 46, 414-431.

Wang, H., S. Schubert, M. Suarez, J. Chen, M. Hoerling, A. Kumar, and P. Pegion, 2009: Attribution of the seasonality and regionality in climate trends over the United States during 19502000. J. Climate, 22, 2571-2590.

Watanabe, M., and Coauthors, 2010: Improved climate simulation by MIROC5: Mean states, variability, and climate sensitivity. J. Climate, 23, 6312-6335.

— , and Coauthors, 2011: MIROC-ESM: Model description and basic results of CMIP5-20C3M experiments. Geosci. Model Dev. Discuss., 4, 1063-1128, doi:10.5194/gmdd-4-1063-2011.

Weaver, S. J., 2013: Factors associated with decadal variability in Great Plains summertime surface temperatures. J. Climate, 26, $343-350$

Yukimoto, S., and Coauthors, 2011: Meteorological Research Institute-Earth System Model version 1 (MRI-ESM1): Model description. MRI Tech Rep. 64, 83 pp. [Available online at http://www.mri-jma.go.jp/Publish/Technical/DATA/VOL_64/ index_en.html.] 